\title{
Heightened Herd Behavior in Financial Market Under Covid-19
}

\section{Battle and Cooperation Among Individual Investors and Institutional Investors}

\author{
Sijin Lyu ${ }^{1}$, Yafan Wang ${ }^{2, *}$, Mengru Zhang ${ }^{3}$ \\ ${ }^{1}$ HongWen School Qingdao, Qingdao, China \\ ${ }^{2}$ Raffles Institution (RI), Singapore \\ ${ }^{3}$ Columbia International College, Hamilton, Canada \\ *Sijin Lyu. Email: lululuciaaa@126.com \\ *Yafan Wang. Email: 21WANG976R@student.ri.edu.sg \\ *Mengru Zhang. Email:1812139202@qq.com \\ These authors contributed equally
}

\begin{abstract}
In recent years, the phenomenon of trouping investors, both individual and institutional, has become more frequent and common in China and the U.S., especially under the circumstance of COVID 19, which has wreaked havoc in all sectors including the financial market. The market has witnessed increased volatility caused by herd behavior among retail investors and institutional investors. This article will focus on the interaction between retailer and institutional investors and the herd behavior within institutional investors. The battle between individual investors and institutional investors can be studied from the GameStop context. Individual investors have banded together from Reddit to push up GME's stock price in an attempt to hurt the Wall Street established big institutional investors who are shorting GME. This demonstrated the rising power of individual investors and the influence of social media. This herd behavior indicates a change in power dynamics in the financial market. The second manifestation of heightened herd behavior would be seen in the banding together among institutional investors in Nasdaq and in China's financial market. In Nasdaq, investors have come together to invest in technology stocks, whereas in China's financial market, big institutions focused on buying A-shares heavily. This coordination and focus have also increased volatility. Thus, the heightened herd behavior under Covid-19 has indicated a change in the power dynamic between individual investors and institutional investors, which caused the increased volatility in the financial market. Individual investors, institutional investors, and the government should take note of such heightened herd behavior and take appropriate actions to guard themselves against this heightened herd behavior.
\end{abstract}

Keywords: Grouping investor, Herd behavior, Gamestop, Stock market

\section{INTRODUCTION}

Can retail investors group together to fight against institutional investors? What are the reasons, results, and consequences of the clustering of both retail investors and huge investment institutions?

The saga of GameStop was a battle between individual investors and institutional investors. This circumstance was due to various reasons, to benefit their own interests like profit, or simply due to emotional factors. These actions taken by the retail investors during the pandemic in 2021 caused a short squeeze, along with allowing GME to have a shocking return of $900 \%$. This was a case of herd behavior within retail investors against institutional investors,

As the individual retail investors are grouping together, large investment institutions are also doing so in other stocks and markets. Herd behavior between investment institutions is when many investment institutions all decide to purchase on one specific stock, that is, when many institutional companies hold a stock 
simultaneously due to their same opinions on the good profitability, growth, and stability of the same stocks.

In the U.S. and China, many institutional investors clustered together not only during COVID 19 but also in many other situations throughout the history of stock markets. Even though the phenomenon appeared in different countries, the main causes and reasons and the consequences were very similar. During the pandemic, investors, including individuals and institutional, all grouped together in a few similar stocks on advanced technology (mainly on NASDAQ in the U.S.), social media, medical facilities, and healthcare. People and institutions all believed these were the fields in which are going to profit and develop over the rigorous and harsh state of affairs. Moreover, factors like the confidence and emotional elements of investors, the overall situation of lack of high-quality funds and stocks, as well as big investment institutions with immense funds that cannot be transferred swiftly in and out of stocks like individuals can, etc. also contributed to aid the occurrence of the phenomenon. Eventually, both positive and negative consequences occurred, impacting both the stocks and funds and the investors.

\section{LITERATURE REVIEW}

Lyócsa et al. found that as the discussion on the Wall Street Bet subreddit intensified, the price variation of the four stocks increased, suggesting that the forum is a major coordination platform of the short squeeze of GameStop AMC and others [1]. Not only that, after investigation and research, Chohan suggested that the reason for the soaring trading volumes of GameStop, AMC, BlackBerry, and Nokia is public resentment towards institutional investors. He framed this event as a public reprisal for the 2008 Global Financial Crisis (GFC) and public contempt for insular financial private interest [2]. Hasso et al. studied the profile of those who participated in the short squeeze frenzy. By using brokerage accounts to study those participating in the Game Stop frenzy, they found that the GameStop frenzy was not a pure digital protest against Wall Street but speculative trading by a group of retail investors, in line with their prior high-risk trading behavior. The trading retail investors' history of engaging in highly risky behavior and the early closing of their GameStop positions indicates that participation in the frenzy was, to some extent, fueled by their desire for gambling [3]. Furthermore, Vasileiou et al. found strong bidirectional causality between GME trading volume and GME performance and a strong one-way causality that runs from Google searches to GME returns by using intraday hourly data and Google Trend Index. Moreover, they employed a GARCH $(1,1)$ model. They found that increases in trading volume and in GME Google searches had a positive and statistically significant impact on GME prices (and vice versa) [4]. Also, Angel suggested that the trade-in option markets fueled the increase in the price of GameStop stock in the stock market. Furthermore, he gave many regulatory suggestions, such as restructuring the tax system to remove incentives to stay short indefinitely, reducing settlement cycles, and allowing retail investors to rent out shares [5].

Many investors have researched the organization of institutional investors. Parry uses statistical analysis, which puts indices returns samples to find out the average daily returns, to determine which exchange provides the highest overall returns to investors based on macroeconomic variables. And it comes out that the NASDAQ's daily rate of return may have fallen the least during the COVID-19 [6]. Besides, Josic compares the daily returns of the New York Stock Exchange (NYSE), New York Stock Exchange, American Stock Exchange (AMEX), and NASDAQ Stock Exchange based on studying stock returns and investment strategies. During the period of economic expansion, the daily return to New York Stock Exchange will be better; However, during the recession, NASDAQ had the smallest decline [7]. In addition, at the end of each year, NASDAQ is rebalanced, and companies that do not meet the criteria will withdraw from NASDAQ. By calculating NASDAQ's cumulative market-adjusted performance, Mackintosh found that besides the index additions, he also benefited from the "new normal" top outliers brought by COVID-19, so these values attracted enough investors [8].

The phenomenon of institutions grouping together is also very serious in China. Wu et al. did some research on the relationship between 'investment institutions grouping together', and the risk of crashes in a stock market. Through some investigations, they found out one would affect the other by a huge margin. They discovered close connections between the shareholding ratio of the institutions and the risk of the stock price collapsing [9]. At the same time, Luo and Dang started with the phenomenon of 'investment institutions grouping together'. They then investigated the structure of network community of institutions, their stability, and the characteristics of the institutions in the community. In the end, they found out that the phenomenon of institutions becoming a small community is becoming more and more frequent. The structures of the communities aren't totally stable, but neither do they change randomly; they are continual and stable. Moreover, the institutions that form in groups are rather stable [10].

\section{Case analysis of GaMeStop}

\subsection{What happened}

At the start of 2021, a group of Amateur retailers, now known as the online "Reddit Bros", staging a war 
with the " Wall Street Pros" by frantically buying up the stocks that were "shorted" by the Wall Streets hedge fund managers, causing these financial establishments to lose huge amount of money. Their concerted buying has pushed the GameStop stock up 1,700 percent since the start of the year, forcing short-sellers such as Melvin Capital to seek a cash injection from allies. This contest soon spread to other stocks heavily shorted by institutional managers such as AMC, BlueBerry, and Nokia.

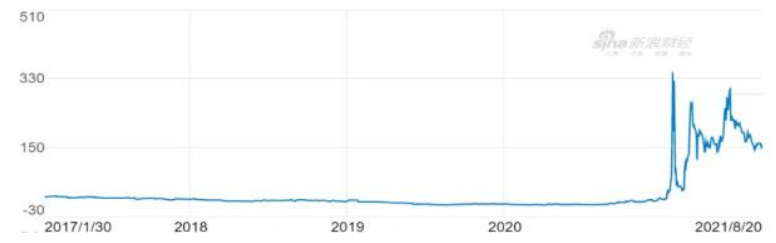

Figure 1 Stock Price of GME

\subsection{Reasons}

\subsubsection{Retail investors' emotional factors}

Many media portray this frenzy as an emotiondriven war between institutional investors and retailers. With the arrival of Covid-19, people in the middle and low strata of society bear the brunt of the economic recession. People may project their misery onto the activities in the financial markets. Thus, the perception that shorting is unethical heightened as people see it as big institutions gloating over some firms' decline and losses. This may appear to be morally unacceptable for many and drove them to band together on social media to "revenge".

However, to what extent is this event attributed to the emotional factors of retailer investors?

To conclude this, we have to examine the rationality of such a spike from an investment point of view. In the GameStop context, increasing the demand for its stocks may not be a rational choice to earn profits based on the firms' current and potential to perform. There are several reasons. Firstly, the GameStop product was primarily physical game sets. This may become outdated as there are many popular substitutes such as online games and promising novel substitutes such as Virtual Reality. Secondly, as Covid-19 became a problem, its sales declined further, and thus it was not good timing in 2020 to purchase its stock theoretically. From the firms' financial report, both the earning per share of the stock and the quarterly growth of the firm is negative, meaning that investors would not choose to invest in its stocks because this firm currently does not reflect profitability and potential to grow. Therefore, given the lack of general profitability in this firm, other factors contribute to this frenzy, and many people have attributed it to the emotional reasons elaborated above.

\subsubsection{Profit-seeking}

Although we analyzed the lack of general profitability of investing in this firm based on its performance, certain groups of people benefit from it.

One group of people that are benefiting from the rise of stock price are existing shareholders of the firms. They could benefit in two ways. One way is to capitalize on this frenzy as it is Ponzi's scheme, sell the stocks when the price is high and leave before it bursts. Another way is like what GME is doing now, issuing new shares to fund its future development, thus increasing its future profitability. In April 2021, GameStop sold 3.5 million additional shares, raising $\$ 551$ million to speed up the company's e-commerce transformation.

The other party that can benefit from this is speculative traders who similarly buy the stock and sell the stock when the price is higher. They thus benefit from the upward spiral of the price increase.

Although it is in the existing shareholder's interests for this rise in price to happen, the fact that a lot of shareholders still take short positions reveals that they do not foresee such a quick rise in price and this spike is thus not intentionally created by them.

Thus, it is more likely for those who participated in this frenzy mid-way to keep fueling it and draw in more people to break the zero-sum game with institutional investors and turn it into a positive-sum game. The sentiment of "combating institutional investors" may then just be their slogan to appeal to those emotionally driven to advance their own gains.

\subsection{Implications}

The battle between individual investors and institutional investors sheds some light on certain changes in the financial markets that we have to bear in mind, namely the influence of the media, the rising power of individual investors, and the philosophical problem of the intrinsic purpose of the existence of the financial market. Those changes have impacts on individuals, institutional investors, firms, and governments and require different responses.

The media plays an undeniably important role in fueling this battle. It plays a role in drawing similarminded people together to devise a plan and stoke the emotions of others to join the plan. With the advent of a wide variety of online social media and worldwide access to it, it is becoming increasingly easier to exchange opinions and coordinated actions. This speed and scale of coordination could cause more herd behavior, less diversity, and increasing volatility.

Every stakeholder in the investment markets should also note the rising power of individual investors. 
Financial technology has made investing easier and more accessible for individuals. There are various trading platforms such as Robinhood, eToro, and many in-app wealth management functions. According to Joe Mecane, the head of execution services at Citadel Securities Retail, retail investors have accounted for as much as $25 \%$ of the stock market's activity amid coronavirus-driven volatility. Still, the group made up just $10 \%$ of the market in 2019 . The proportion steadily climbed as brokers slashed commission fees and the pandemic fueled violent price swings. This rise of individual investors may increase the vitality of the financial market further.

The philosophical problem of the intrinsic purpose of the existence of the financial market should be reexamined, namely if the financial market mainly aims to raise funds for firms with the potential to grow or it is acceptable to be the battle of games and gambles to advance personal interests.

\subsubsection{Individual Investors}

Individual investors should be mindful of the influence of the media. While the media makes information and coordination easier, it is a double-edged sword and may flood them with inaccurate information and exploit their feelings and induce certain irrational behavior. Thus, they should be more vigilant about the information they receive on social media.

The ease of access to those financial platforms for those individuals requires more personal wealth management. A lot of platforms allow them to indicate their risk tolerance level and set margin rates by themselves. The onus is on themselves to be properly informed with financial knowledge and their own wealth.

From the individual's perspective, the philosophical problem of the existence of the financial market is less relevant. They just have to choose the best strategy to maximize their profits.

\subsubsection{Institutional Investors}

The frenzy suggests that institutional investors should be more sensitive about social media trends and be more agile to avoid losses. Social media also represents an opportunity for them to deliver certain social media messages and increase their influence.

Gone are the days where institutional investors only needed to crunch data and monitor the performance of the firms, the sentiments of the investors in the financial market became more important, and they should keep a close eye on how people feel and the ripple effects of people's feelings.
As they often invest on others' behalf, they should be more careful about their clients' demands and avoid risk-taking and be agile. For example, if they are managing pension funds, they should aim for more stable assets and not under the spotlight of public attention

\subsubsection{Firms}

Firms can utilize the media to reach a broader consumer base and a border investors' base. They could develop new marketing strategies targeting investors or make the firm's stocks become one of the meme stocks, though the risks are their own. This perhaps points to a more effective way for managers to increase their firms' market value by catering to public sentiments and encouraging herd behavior to buy their stocks by carrying our social media campaign.

\subsubsection{Government}

Undeniably, there are a lot of areas that the government should look into.

As the stock price of GME rises, the google search volume of GameStop also rises, as shown in Figure 3. This shows that the media attention of GameStop might have directly led to the success of the banding together of the "Reddit Bros". This means that social media has played an increasingly important role in influencing people's decisions and the financial market. While increased accessibility of social media may eradicate information asymmetry, it has also made people more vulnerable to manipulation and fake news. Therefore, the government should regulate fake news and market manipulation. It could possibly expand existing fake news regulations such as the Protection from Online Falsehood and Manipulation Act in Singapore to financial markets to sheave out the manipulators who do not care about financial stability.
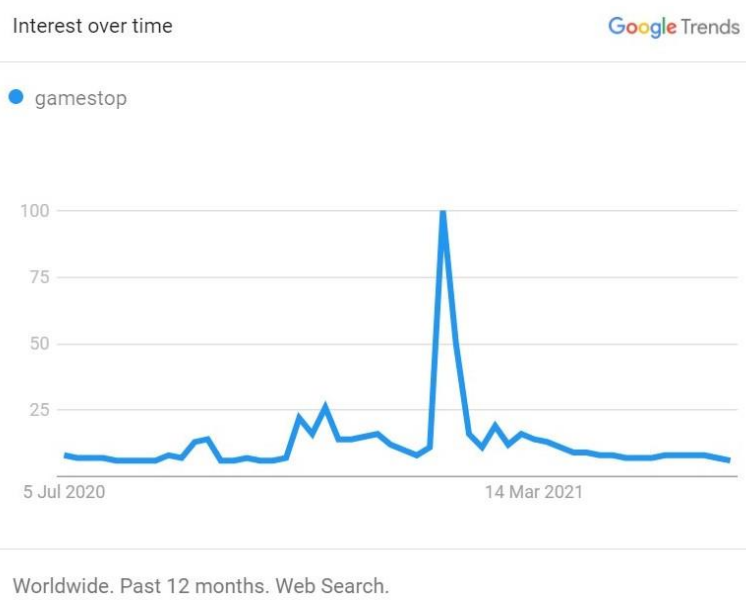

Figure 2 Google Trend Interest Over Time on GameStop 
For the rise of individual investors, the government should impose more regulations from the FinTech firm side. It could possibly impose a universal standard of setting different margin rates based on certain parameters of individuals, such as their current wealth and income. It could also impose trade volume limits on those trading platforms. Some may argue that this has backfired the effort to reduce trade on meme stocks, as evidenced by how the limit imposed midway on Robinhood incited rage and dissatisfaction from the public. This was because the limit was set midway and under no clear guidelines, so it was seen as an impromptu effort from the regulators to stymie their personal gains. Suppose a limit on trade volume can be set before any fluctuations happen, with clear guidelines and evidence of its necessity. In that case, it may help to reduce the volatility brought by individual investors.

For the problem of if the financial market should mainly be platforms for firms to raise funds or battlefields for personal gains, the general sentiment is that games for personal gains are acceptable as long as it does not trump the aim to raise the fund for firms with the genuine capability to grow. In other words, those two aims are not mutually exclusive, so regulations have to be put in place carefully to balance those two aims. Some nudges that the government can do are to educate the public about investing and make information on the performance and potential of firms more understandable and accessible to the public. At the same time, it could consider the above regulation recommendations to further limit the borrowing and trade volume on individual investors. Nevertheless, no matter what regulations it carries out, it should bear in mind what gets this all started-the emotional sentiment of unfair treatment between institutions and individuals. Thus, it could be especially careful about designing policies that ensure a fair and less volatile playfield for all.

\section{THE ANALYSIS AND RESEARCH ON THE HERD BEHAVIOR WITHIN INSTITUTIONAL INVESTORS OF CHINESE AND AMERICAN INSTITUTIONS}

\subsection{What happened}

The situation of institutions grouping together is relatively prevalent around the globe. However, recently, due to the pandemic COVID 19, the herd behavior between institutional investors has become more and more common. This phenomenon will cause huge impacts, positive or negative, on both the stock market and the stock itself that's being purchased by numerous amounts of institutions.

\subsubsection{Institutions grouping together in the U.S.}

Many stocks have been heavily affected by COVID19 since 2020. The institutions tended to favor some stocks with stable performance. Therefore, the NASDAQ 100 Index performed strongly in the face of the virus pandemic. Therefore, more and more people are paying more attention to large technology companies such as Apple, Amazon, Tesla, and digital companies such as Facebook.

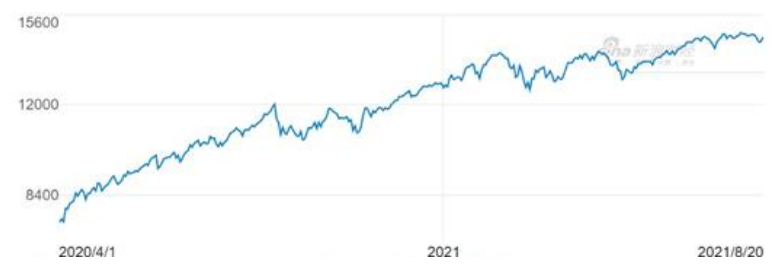

Figure 3 The performance of the Nasdaq index in the past year (April 2020 - August 2021)

\subsubsection{Institutions grouping together in China}

Similarly, the institutions' grouping also appeared in A stock, which is very common around China, especially since the occurrence of COVID 19. However, the situation may also disappear very quickly and swiftly, and the phenomenon is not stable. It probably will not last for a very long period. Some institutions will eventually stop purchasing a specific stock. When there is a disagreement in the market, the aesthetics are no longer so consistent, the funds and institutions will go elsewhere from the group stocks, and the money will flow away. Therefore, the stock price will naturally drop back, which then causes the 'special situation' to go away.

Even though the situation might not last very long, it will still bring significant impacts to all members of the stock market, which are both positive and negative.

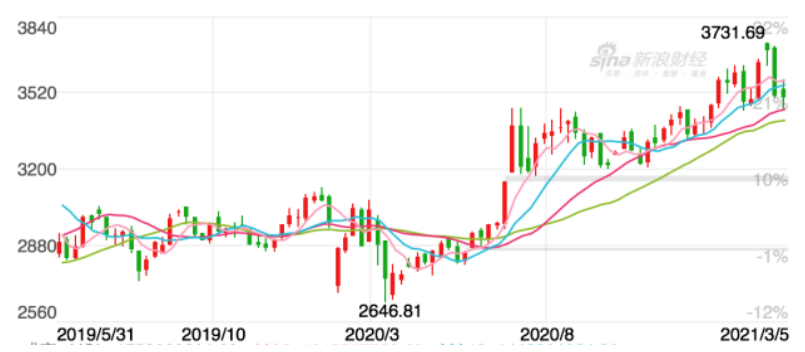

Figure 4 The index number of SSE 50 (May 2019 March 2021)

\subsubsection{Stock price crashes}

First of all, a negative impact is that institutional investors huddle together has a high rate of causing stock price crashes. Information and data indicate that the proportion of stock held by institutional investors that are grouped together closely affects the possibility of market price crashes. Moreover, when specific enterprises which are private, highly protective of the investors, and have high agency costs, their proportion of stock held by institutional investors who are huddled 
together will have even bigger impacts on the risk of stock price crashes.

\subsubsection{The rise in profits and stock prices}

Furthermore, this phenomenon will trigger a significant and dramatic rise in the profits and the stock prices of the enterprises which are being bought by the numerous amount of institutional investors, which are then identified as being grouped together. The dramatic rise might then attract even more investors to purchase the stock. However, eventually, some institutions will stop purchasing a specific stock. When there is a disagreement in the market, the funds and institutions will go somewhere else from the group stocks, and the money will flow away. Therefore, causing the stock price to naturally drop back.

\subsubsection{Other stocks in the market}

When institutions and funds are grouped together when investing, it will create an illusion for people that the stock market might be developing and growing. However, the truth is that only the stocks being bought by most investors are growing. This will trigger all the other stocks on the market to crash and decline.

\subsection{Reasons}

The phenomenon of funds and institutions huddling together is happening in both the U.S. and China, but various reasons and causes lead to it.

\subsubsection{Reasons for the clustering of firms in the U.S.}

\subsubsection{Pandemic implication}

Due to the impact of the virus pandemic, the US government has launched a lockdown policy. This policy has led to an increase in the trend of people working from home and shopping online. People need to stay indoors and buy all the necessities online, which has greatly promoted the e-commerce industry.

Also, because of the growth of digital network payment, the increment of video traffic, and the soaring and popularity of video game sales, these will gradually become the new normal trend in people's lives. To keep people away from each other during the pandemic, many industries are booming. For example, in the video game industry-more and more people are playing video games for indoor entertainment.

And given the intensification of the pandemic in the United States, investors believe that the Internet and the technology industry will continue to be the major needs of everyday life in the future.

\subsubsection{Investors' confident}

Since May this year, the US government has started the economy. As states gradually resume production and resume work, the three largest U.S. stocks will continue to rise. The S\&P 500 index, the Dow Jones index, and the NASDAQ index rebounded $31.17 \%, 49.51 \%$, and $44.71 \%$, respectively, from their lowest points. At the same time, technology stocks have become the leading force in the U.S. economic recovery. Among them, Apple, Microsoft, Amazon, Google, and Facebook, the five largest technology stocks, have increased their valuations by 1.2 trillion in the past, which indicates that investors are full of confidence in the technology company's ability to recover from the epidemic.

\subsubsection{Institutional profile}

Since the funds the institutions earn are management fees, not stock returns, and the most important thing is to be stable, they often invest their funds in leading stocks with large market value. These institutions usually choose stocks with high growth and good fundamentals because such stocks have great growth potential. And eventually, with the continuous strengthening of institutional groups, the number of retail investors in the market will be less and less.

\subsubsection{Reasons causing funds to group together in China}

\subsubsection{Lack of high-quality underlying stocks}

In addition, a major reason for the clustering of institutions is the lack of high-quality underlying stocks, so most institutions will choose to buy stocks with great potential and stable performance, and this is the main reason for the clustering of funds during the pandemic, in 2019 and 2020 in China. The epidemic's impact in 2020 has made the markets worldwide suffer heavy losses, and most industries have suffered losses or even stagnated, seriously affecting the development of relevant industries. While investment institutions, to make as much profit as possible, stuck together to invest in only a few stocks that were developing and growing, such as enterprises that focus on medical facilities and health care.

\subsubsection{Institutions with huge funds}

Another "contributor" to the institutions' grouping phenomenon is the huge funds of the investment institutions. They cannot transfer funds in and out as quickly as retail investors, and their performances are under huge pressure. This has caused many institutions to just follow the trend and purchase high-quality stocks in the current market and to buy the stocks bought by other institutions, resulting in the phenomenon of 
institutions clustering. In addition, to manage their huge funds that cannot be transferred at a fast speed, they all prefer to invest in firms with high liquidity.

\subsection{Implications}

Differences in the phenomenon of investment institutions grouping together in the U.S. and in China

The main difference in the clustering of institutions in the two different countries is mainly the reason for the phenomenon. In the U.S., it was the retail investors grouping together to 'fight' against the institutions. Meanwhile, in China, COVID 19 caused a huge deficit of high quality and profitability stocks, which caused the funds to go into the few developing enterprises.

\subsubsection{Similarities of the situations in the U.S. and in China}

Despite the huge differences, there are indeed similarities. Such as, both situations lead to very similar outcomes. The enterprises all had a moment when their stock prices were incredibly higher than all the other stocks in the market, and later, predictably, their prices dropped back to normal.

\subsubsection{Trend}

America's stock market is already pretty much stable. The number of firms and stocks has a high probability of maintaining around the same. Therefore, based on current assumptions, the phenomenon of investment institutions grouping together will continue to appear frequently in the U.S., just as how it is occurring nowadays.

As for the situation in China, a developing country, people predict and believe that its number of stocks will grow continuously due to its development in technology and various other fields. Hence, there will be increasingly more stocks with high quality and profitability, which will alleviate the problem of institutions grouping together.

\section{CONCLUSION}

To conclude, by examining the GameStop Case Study and the highly coordinated investment in both China and America markets, we pointed out the heated coordination and herd behavior in the stock market under Covid-19. From the GameStop Case Study, the market witnessed the rising power of individual investors and how social media increased connectedness to amplify its impact on the financial market. From the high coordination between institutional investors in the China and America market, this study attributed those behavior to lack of quality stocks and concentrated social focus. These have all led to the increased volatility in the financial market and shed light on the power dynamic between retail investors, institutional investors, and the governments.

\section{REFERENCES}

[1] Lyócsa, Š., Baumöhl, E., \& Vŷrost, T. (2021). YOLO trading: Riding with the herd during the GameStop episode. EconStor Preprints.

[2] Chohan, U. W. (2021). Counter-Hegemonic Finance: The Gamestop Short Squeeze. Social Science Research Network.

[3] Hasso, T., Müller, D., Pelster, M., \& Warkulat, S. (2021). Who participated in the GameStop frenzy? Evidence from brokerage accounts. Finance Research Letters, 102140.

[4] Vasileiou, E., Bartzou, E., \& Tzanakis, P. (2021). Explaining Gamestop Short Squeeze using Intraday Data and Google Searches. Social Science Research Network

[5] Angel, J. (2021). Gamestonk: What Happened and What to Do about It. Social Science Research Network.

[6] Parry, Trevor. "NYSE, AMEX, and NASDAQ Stock Exchange Returns." SSRN, 29 Dec. 2020, papers.ssrn.com/sol3/papers.cfm?abstract_id=3730 161.

[7] Jošić, H. (2020, June). USING MACHINE LEARNING TOOLS IN NASDAQ COMPOSITE STOCK MARKET INDEX PREDICTION. In Proceedings of FEB Zagreb International Odyssey Conference on Economics and Business (Vol. 2, No. 1, pp. 312-323). University of Zagreb, Faculty of Economics and Business.

[8] Mackintosh Phil Mackintosh, P. (n.d.). What Happens to Stocks Added to the Nasdaq-100? Nasdaq. https://www.nasdaq.com/articles/whathappens-to-stocks-added-to-the-nasdaq-100-202103-18

[9] Wu Xiaohui, Guo Xiaodong, \& Qiao Zheng. (2019). Institutional investor grouping and the risk of stock price collapse. China Industrial Economy, 2, 117-135.

[10] Ji, L., \& Xinghua, D. (2016). Study on China's VC Network Communities: Structure Recognition, Dynamic Evolution and Preference Features. Management Review, 28(5), 61. 